\title{
O ENSINO DO DIREITO NA FRANÇA ${ }^{1}$
}

\author{
Michel Miaille e Fernando de Castro Fontainha
}

\section{RESUMO}

O PRESENTE ARTIGO TEM POR OBJETIVO ANALISAR O ENSINO JURÍDICO NA FRANÇA. NOSSO OLHAR É GUIADO POR UMA DUPLA PERSPECTIVA: A DISTINÇÃO ENTRE FACULDADES CRÍTICAS E MUNDANAS E A NOÇÃO DE CRISE, TRAZIDA DA CIÊNCIA POLÍTICA. APÓS BREVÍSSIMA INTRODUÇÃO HISTÓRICA, DEMONSTRAREMOS COMO, NAS DUAS METADES DO SÉCULO XX, O ENSINO JURÍDICO SE DESENVOLVEU E PRODUZIU O QUE CHAMAMOS DE MODELO CLÁSSICO DE ENSINO DO DIREITO. NOSSO FOCO, A PARTIR DESSA DUPLA PERSPECTIVA, APONTA PARA UMA DINÂMICA EM QUE GRANDES TRANSFORMAÇÕES SOCIAIS CAUSAM SIGNIFICATIVO IMPACTO NA UNIVERSIDADE FRANCESA, E, EM CONTRAPARTIDA, PARA COMO O CORPO DE JURISTAS, A FIM DE SE MANTER NA POSIÇÃO DOMINANTE, CONSEGUE TRANSMITIR, ATRAVÉS DAS CRISES, OS ELEMENTOS QUE GARANTEM ESSA DOMINAÇÃO, CALCADOS NAS ESPECIFICIDADES DA CIÊNCIA JURÍDICA. O CONCEITO-CHAVE PARA COMPREENDER ESTA DINÂMICA E QUE AO FIM PRODUZIRÁ O MODELO CLÁSSICO É O DE HERANCA, TAMBÉM TRAZIDO DA CIÊNCIA POLÍTICA. EM CONCLUSÃO, TENTAREMOS CONFRONTAR ESSA DINÂMICA COM AS QUESTÕES QUE - ENSINO JURÍDICO FRANCÊS ENFRENTA HOJE - MORMENTE RELACIONADAS À PERDA DE CENTRALIDADE DA DISCIPLINA LANÇANDO O QUESTIONAMENTO DE COMO ESSA NOVA CRISE SERÁ ENFRENTADA PELAS FACULDADES DE DIREITO.

\section{PALAVRAS-CHAVE}

ENSINO JURÍDICO; CRISE POLÍTICA; FACULDADES MUNDANAS; HERANÇA POLÍTICA; CAMPO UNIVERSITÁRIO.

\section{ABSTRACT}

THIS ARTICLE AIMS TO ANALYSE THE LEGAL TEACHING IN FRANCE. OUR APPROACH IS GUIDED BY A DOUBLE PERSPECTIVE: THE DISTINCTION BETWEEN CRITICAL AND MUNDANE SCHOOLS AND THE NOTION OF CRISIS, BROUGHT FROM POLITICAL SCIENCE. AFTER A BRIEF HISTORICAL INTRODUCTION, WE WILL DEMONSTRATE HOW, IN THE TWENTIETH CENTURY, THE LEGAL TEACHING DEVELOPED ITSELF AND PRODUCED WHAT WE CALL "CLASSICAL LEGAL TEACHING MODEL". OUR FOCUS, DEPARTING FROM THAT DOUBLE PERSPECTIVE, AIM TO A DYNAMICS WHERE GREAT SOCIAL TRANSFORMATIONS CAUSE STRONG IMPACT IN FRENCH UNIVERSITY AND, ON THE OTHER HAND, HOW THE BODY OF LAW SCHOLARS, TO KEEP THEIR DOMINATION POSITION, GET TO TRANSMIT THROW THE CRISIS THE ELEMENTS THAT GUARANTEE THAT DOMINATION, ON THE "LEGAL SCIENCE SPECIFICITIES" PRETEXT. HERITAGE IS THE POLITICAL SCIENCE BROUGHT KEY-CONCEPT TO UNDERSTAND THAT DYNAMICS AND THE CLASSIC MODEL PRODUCTION. OUR CONCLUSION IS AN ATTEMPT TO CONFRONT THAT DYNAMICS WITH THE ISSUES THAT THE LEGAL TEACHING FACES NOWADAYS - SPECIALLY THE DISCIPLINE LOSS OF CENTRALITY - ASKING THE QUESTION OF HOW THIS NEW CRISIS WILL BE FACED BY THE LAW SCHOOLS.

\section{KEYWORDS}

LEGAL TEACHING; POLITICAL CRISIS; MUNDANE SCHOOLS; POLITICAL HERITAGE; UNIVERSITY FIELD.

\section{INTRODUÇÃO}

O tema ensino jurídico poderia ser objeto de várias lógicas e disciplinas, como a história, a sociologia da educação ou a ciência política. Igualmente, o direito objeto deste 
ensino, pode ser visto sob diversas óticas, como a tradicional (as disciplinas jurídicas, onde o direito explicaria a si mesmo), a da sociologia ou a da ciência política. Neste breve ensaio, não pretendemos tudo dizer, mas pretendemos construir uma problemática capaz de servir de fio condutor, sob uma dupla perspectiva:

a) Segundo a distinção elaborada por Kant (1973) e retomada por Bourdieu em seu livro Homo academicus, há que se distinguir as faculdades entre as críticas e as mundanas. Entre as faculdades críticas estariam os cursos de letras, filosofia e ciências naturais. Eles merecem essa denominação pelo caráter de liberdade e autonomia intelectual. Por outro lado, as faculdades mundanas, como o direito e a medicina, são profundamente marcadas pela consolidação de um corpo sempre ligado ao poder estabelecido, como demonstrado por Arnaud no seu livro Les juristes face à la société - o que nos remete à ideia de crise.

b) Tomamos emprestado de Michel Dobry o conceito de crise desenvolvido no seu livro Sociologie des crises politiques. Para o autor, entende-se por crise os momentos em que a continuidade e a estabilidade da reprodução da organização social, sobretudo da que nos parece "automática", encontram-se ameaçadas.

Pretendemos demonstrar como, sempre a serviço dos dominantes, o ensino jurídico é obrigado a reformular suas condições de sobrevivência e seu destino meio a um emaranhado de obstáculos que destroem os antigos modos de proceder, sem indicar claramente quais as possibilidades futuras.

\section{Breve história do ensino JuRÍdico na FrançA}

Datando dos séculos XI e XII, o ensino jurídico conhecerá em Paris e Montpellier sua primeira geração de faculdades (no âmbito europeu, citamos também Bolonha e Oxford). Na Idade Média e no Antigo Regime, as faculdades de direito, extremamente ligadas ao direito canônico e apegadas aos textos romanos, cumprirão o papel de formação das elites, sobretudo as elites de Estado.

A Revolução de 1789 vai extinguir as faculdades existentes, e Napoleão I refundará o ensino universitário sob bases autoritárias: assim como o exército, a Universidade imperial era um todo dirigido de forma rígida e uniforme, como as demais instituições imperiais. As universidades do Antigo Regime darão lugar a faculdades monodisciplinares e autônomas do ponto de vista intelectual. À união administrativa de quatro faculdades deu-se o nome de universidade. Para as faculdades de direito, especificamente, foi reservado o papel de prestar uma formação técnica e prática, sobretudo após a unificação do direito nacional pelas codificações napoleônicas.

Assim, o ensino jurídico francês no século XIX será marcado por um duplo monopólio: o das faculdades de direito como um aparato estatal - monopólio este 
baseado na exclusividade da certificação dos profissionais em direito - e o das disciplinas "puras" e "duras", como o direito civil e romano.

Desde a Idade Média até o período revolucionário o ensino jurídico francês viveu crises. Nosso foco será o século XX, sendo a descrição anterior necessária para a compreensão de como esse ensino chega ao início do século.

\section{A CRise do século XX (PRimeira metade)}

A primeira metade do século XX foi marcada por duas tímidas porém relevantes reformas, embora elas não tenham transformado sensivelmente o antigo modelo.

A primeira delas ocorreu entre 1905 e 1924 e trouxe como principal inovação a obrigatoriedade da avaliação por exames orais e escritos, valendo ressaltar que, desde a Idade Média, as faculdades de direito utilizavam as provas orais como único meio de avaliação (à exceção das teses). Sem mencionar o quão mais difícil é diferenciar um estudante sob o ponto de vista social, econômico e étnico em uma prova escrita que em uma prova oral, os juristas resistiram o quanto puderam a esta inovação a bem da "especificidade" do ensino jurídico. A despeito dessa resistência, a novidade foi incorporada nas faculdades de direito. O que se pôde observar foi a designação dos professores mais jovens ou minoritários para as tarefas de correção dos exames escritos.

A segunda reforma, de 1954, pretendeu modificar o currículo do curso de direito, a fim de torná-lo mais "crítico". Na verdade, o que ocorreu foi uma mudança do nome das disciplinas. Então, por exemplo: direito constitucional passou a se chamar direito constitucional e ciência política; em vez de direito administrativo passou a se adotar direito administrativo e ciência administrativa; e direito penal se tornou direito penal e ciências criminais. Podemos chamar as modificações trazidas pela reforma de falso criticismo. Não bastava tentar produzir do alto a discussão multidisciplinar, os professores deveriam abraçá-la. Fato é que, ao contrário, o corpo docente era extremamente resistente às disciplinas que consideravam como "anexas" ao direito. Uma interessante demonstração dessa resistência pode ser dada a partir da prática docente do jurista Jean Carbonnier, um dos mais progressistas de sua época. Quando ministrava seu curso de direito civil, ele usava a toga, porém não o fazia quando ministrava sociologia jurídica.

Porém, não apenas deméritos teve a reforma de 1954. Ela também instaurou os trabalhos dirigidos como forma de curso. Vale salientar que o modelo tradicional de curso através de cursos magistrais se mantinha desde a Idade Média, sendo um curso magistral uma aula em anfiteatro lotado, em ambiente impessoal, formal e teatral. Os trabalhos dirigidos, por outro lado, se davam num ambiente de mais proximidade e diálogo. Se os cursos magistrais ainda existem na França, hoje é comum que doutorandos sejam recrutados para ministrar os trabalhos dirigidos.

Mesmo as duas reformas não foram suficientes para gerir uma crise, provocada por um modelo de ensino não adaptado à nova conformação humana . 


\section{A CRise do século XX (SEgunda metade)}

A grande crise ocorrida no século XX se deve ao confronto de um modelo que pouco mudou desde o século XIX com o fenômeno da massificação do ensino universitário na França.

De todas as transformações que o pós-guerra trouxe à sociedade francesa, o grandioso aumento do número de estudantes é uma das mais relevantes. A “democratização" do acesso à universidade NA França, que não dependeu de nenhuma reforma ou ato formal e perdurou por todo o século, pode ser percebida por números impressionantes. Damos o exemplo da Faculdade de Direito de Montpellier, célebre berço de uma restrita elite local: na década de 1960 já recebia espantosamente trezentos alunos por ano e atualmente recebe mais de dois mil. Porém, essa massificação não trouxe apenas mudanças quantitativas no corpo estudantil. Duas mudanças qualitativas importantes vão ocorrer e tornar violento o convívio do modelo antigo com a nova configuração humana. Houve uma enorme diversificação da origem de classe dos alunos. Um ambiente formador de uma pequena elite de filhos da aristocracia e da burguesia assiste à entrada massiva da pequena burguesia e de setores do operariado nas salas de aula. Portanto, um setor majoritário torna-se minoritário, e a universidade se vê confrontada com novos hábitos, valores e visões de mundo.

Simultaneamente, ocorre também uma transformação no tocante ao gênero: a feminização. Um universo eminentemente masculino se vê tomado por mulheres, que hoje compõem a maioria esmagadora dos bancos universitários nas Faculdades de direito. Um dos impressionantes números que servem para ilustrar e demonstrar as consequências desse fenômeno merece ser citado: mais de $80 \%$ da magistratura francesa é hoje composta de mulheres, muito embora na Corte de Cassação - sua mais alta corte - elas sejam menos de 20\%. Para que se tenha uma ideia do caráter machista desse meio social, era comum o uso do ditado "toga sobre vestido não vale" (robe sur robe ne vaut), ${ }^{2}$ que caiu por terra, tendo em vista o desempenho das meninas na distribuição de prêmios (em Montpellier, menos de 10\% dos laureados eram do sexo masculino), inclusive na do mais prestigioso: o prêmio de tese. Os prêmios por mérito universitário, tradicionais nas faculdades de direito, vale citar, conheceram um período de "esquecimento" no pós-68.

De todas as manifestações, revoltas e movimentos populares que agitaram a França no século XX, nenhum pode ser comparado ao ocorrido em maio de 1968. Em reação a mais de dez anos de hegemonia gaulista, em 13 de maio de 1968 o movimento estudantil parisiense organizou grandes manifestações por toda a cidade. Seu alvo: o capitalismo, o imperialismo, os valores da velha sociedade, o regime gaulista e a "velha universidade". Esse movimento é tratado por alguns como espontâneo, pois ganhou rapidamente dimensões não esperadas, recebendo prontamente a adesão maciça do movimento sindical e não tardando a mobilizar vários setores da sociedade em todo o território nacional. Maio de 68, como ficou conhecido, imortalizou 
slogans tais qual "É proibido proibir”. Além de diversos outros, o movimento também adotou o slogan "Fim da Universidade".

De todas as transformações que se passaram na França em decorrência de Maio de 68, aquelas relativas às universidades estão entre as mais relevantes (e, sem dúvida, mais pertinentes a este ensaio). Nada tardou para que a antiga estrutura das universidades fosse radicalmente transformada. Em novembro de 1968 entra em vigor a Lei Edgard Fauré, alterando a arquitetura do ensino universitário francês. De início, o sistema nacional é abolido e cada universidade passa a ser dotada de autonomia financeira, administrativa e, sobretudo, intelectual. As faculdades também veem seu fim, uma vez que as universidades se tornam centros multidisciplinares. No lugar das faculdades a lei cria as Unidades de Formação e Pesquisa - Unités de Formation et Recherche (UFR).

Mais uma vez, os juristas tentaram escapar da nova regra geral para as universidades sob o pretexto da "especificidade" do ensino jurídico. Em vão. O que se pratica, no entanto, é um acordo de gestão em que uma UFR não interfere na outra (ou não dialoga com a outra). Christophe Charle (1994) chega a afirmar que a Lei Fauré tornou evidente o fato de que o corpo de professores de direito se vê e se comporta como um corpo à parte, e não como membro de novas universidades, de maneira que a inserção das faculdades de direito nessas novas instituições as torna impossíveis enquanto universidades.

No tocante ao corpo docente, também deve ser exposta uma importante modificação: a transformação dos mestres assistentes em mestres de conferências. Diferentes dos seus predecessores, estes têm a si atribuída uma carga horária igual à dos professores agregados, nenhuma subordinação em relação aos mesmos, porém algumas prerrogativas a menos, como a de orientar teses. Essa transformação, bem como a nacionalização dos concursos de agregação, permitiram que a carreira do magistério em direito fosse passo a passo permeada pela pequena burguesia e até mesmo por camadas mais populares, em substituição a um corpo constituído quase que exclusivamente por filhos de grandes famílias.

Maio de 68 e suas consequências transformaram a universidade francesa, mas não a ponto de impedir que um modelo de ensino jurídico "clássico" chegasse à década de 1980 e aos nossos dias.

\section{O MOdelo Clássico de Ensino do Direito (A HerançA)}

Fazemos aqui o mesmo uso que Pierre Victor Tournier fez do conceito de herança na política. Diferente do que ocorre quando do uso corrente do termo, em direito das sucessões, o que se transmite entre as gerações nem são "coisas", nem permanece o mesmo. Na visão de Tournier também podem se chamar de herança hábitos, usos, ideias e sentimentos transmitidos através de gerações, mesmo se essa transmissão 
acarreta certo grau de modificação do que foi transmitido. É por essa razão que se pode chamar o atual modelo de ensino jurídico francês de um modelo clássico. Esse modelo clássico pode ser mais bem demonstrado sob dois pontos de vista: o da organização dos estudos e o da summa divisio.

Sob o ponto de vista da organização dos estudos, o que podemos observar é um percurso iniciático e uma progressão, na transmissão do conhecimento, do simples ao complexo. Dizemos percurso iniciático porque o currículo do curso de direito é organizado de forma rígida e estruturada. Rígida, pois o estudante pode ir do primeiro ano de licença ao doutorado quase sem efetuar escolhas sobre a sua formação. A faculdade o confronta com "o que se precisa saber" para ser um jurista; e estruturada, pois as disciplinas são encadeadas na forma de pré-requisitos umas das outras, como se uma fosse a base da outra. Esse encadeamento e a coesão pretensamente lógicos entre as matérias - onde o direito privado e, sobretudo, o civil são os pilares centrais garantiriam a coerência, a seriedade e a "especificidade" do diploma em direito. É nas "disciplinas-base" dessa cadeia que encontramos a chamada progressão do simples ao complexo. No currículo do curso de direito, as disciplinas ditas introdutórias teriam por função introduzir conceitos "básicos", como a família ou o Estado, para que estes fossem mais adiante tratados "criticamente" nas disciplinas mais avançadas, mais técnicas. Esta falsa simplicidade - calcada no método cartesiano - já fora denunciada por Bachelard no seu livro Le nouvel esprit scientifique.

Nosso outro ponto de vista remonta aos tempos romanos: a tradicional summa divisio, divisão fundamental do direito em direito público e direito privado. $\mathrm{O}$ atual modelo francês de ensino jurídico ultrapassa a questão de usar essa distinção como explicação das coisas, como uma visão de mundo e como a imposição de uma ordem legitima; ele vai além. Pedagógica e administrativamente é esta a divisão básica nas faculdades de Direito. A despeito da existência dos departamentos de Ciência Política e História do Direito, desde cedo os alunos já começam a formar uma identidade de publicista ou privatista, o que já é consolidado entre os docentes. É apenas em algumas atividades de pesquisa em direito que, nos últimos anos, podemos perceber tímidas iniciativas que unem publicistas e privatistas.

A complexização de categorias "simples", como a família e o Estado, bem como a insuficiência da summa divisio como explicação plausível para as complexas questões que os dias de hoje trazem a nós apontam para uma crise contemporânea do ensino jurídico na França.

\section{CONCLUSÃO: UMA CRISE CONTEMPORÂNEA DO ENSINO JURÍDICO?}

Sempre que se depara com uma crise, o corpo de docentes em direito usa o discurso da "especificidade" da disciplina para tentar reduzir tanto quanto possível o potencial de transformação dela. Ainda que os docentes sejam forçados a incorporar 
mudanças, a resistência cotidiana vai privilegiar os velhos hábitos e o status quo. $\mathrm{O}$ ensino do direito é assim, condenado a viver crises, ou viver em crise. Talvez esta seja sua especificidade: um tipo bem peculiar de conservadorismo que se põe em marcha. Um conservadorismo o qual procura se fechar dentro de si, sendo um sistema que, além de precipuamente existir para explicar a si mesmo, tenta submeter as questões do seu tempo e do seu espaço à sua lógica.

Em um mundo em que a economia, a religião, a família, o Estado, o trabalho, entre muitas outras categorias tratadas tradicionalmente pelo direito, encontram-se sofrendo profundas modificações, outro cenário de crise se anuncia. Um dos sintomas desta crise é a perda de centralidade do direito. Isso se percebe não apenas pela quebra do monopólio dos juristas na produção de discursos sobre o direito, mas também quando outras áreas do conhecimento se tornam pioneiras na produção de discursos sobre categorias tradicionalmente legadas aos juristas.

Vemos os economistas como pioneiros e hegemônicos da discussão sobre regulação, assim como os administradores no tocante à gestão de instituições privadas e públicas, os cientistas políticos sobre a organização do Estado e o direito da integração, e os sociólogos no que se refere à interpretação e ao uso das normas jurídicas e também das novas formas de organização do trabalho, inclusive do trabalho jurídico. Um caso interessante e que corrobora esta hipótese é o da formação jurídica que se ministra nos Institutos de Estudos Políticos (IEPs), sobretudo no de Paris, o Sciences Po Paris. Desde muito instituições dedicadas ao ensino e à pesquisa em Ciência Politica, nos últimos anos os IEPs passaram também a formar juristas altamente competitivos, a julgar pelos resultados dos últimos concursos para ingresso na magistratura francesa. Não à toa que desde 2004 o Sciences Po Paris está autorizado a expedir diplomas de mestre em direito, e desde 2007 seus egressos podem ser aprovados no exame de admissão para a profissão de advogado, o que causou certo constrangimento entre os juristas.

Ao que tudo indica, a resposta da "especificidade" do ensino do direito o mergulhará no anacronismo. Não apenas a abertura à multidisciplinaridade, mas também a revisão das bases do ensino jurídico nos parece imperativa.

: ARTIGO APROVADO (19/07/2010) : RECEBIDO EM 09/07/2009 


\section{NOTAS}

1 Baseado no curso de mesmo nome ministrado por Michel Miaille no Rio de Janeiro (2007), em Roma e em Istambul (2008).

2 Vale ressaltar que o ditado original era "robe sur robe ne vaut" ("robe sobre robe não vale", numa tradução literal), sendo que a palavra robe é usada, em francês, para designar tanto um vestido feminino quanto a toga dos magistrados e dos professores de direito.

\section{REFERÊNCIAS BIBLIOGRÁFICAS}

ARNAUD, André-Jean. Les juristes face à la société. Paris: PUF, 1975.

BACHELARD, Gaston. Le nouvel esprit scientifique. Paris: Quadrige; PUF, 1991.

BOURDIEU, Pierre. Homo academicus. Paris: Minuit, 1984.

CHARLE, Christophe. La république des universitaires: 1870-1940. Paris: Seuil, 1994.

DOBRY, Michel. Sociologie des crises politiques: la dynamique des mobilisations multisectorielles. Paris: Presses de la FNSP, 1986.

KANT, Emmanuel. Le conflit des facultés. Paris: Vrin, 1973.

\section{Michel Miaille}

35 rue des Tresoriers de la Bourse 34000 Montpellier France michel.miailleauniv-montp1.fr

20 rue de l'Université 34000 Montpellier France fontainha.fernandolagmail.com
Doutor em Direito Público Pela Université de MontPellier 1 Professor Emérito da Université de MontPellier 1 LÍDER DA EQUIPE DE RECHERCHE SUR L'IDENTITÉ ET LA Citoyenneté - ERIC, vinCuladA À ÉCOLE Doctorale dA

FACULTÉ DE DROIT

\section{Fernando de Castro Fontainha}

$$
\begin{array}{r}
\text { Mestre em Sociologia e Direito Pela } \\
\text { Universidade Federal Fluminense } \\
\text { doutorando em Science Politique Pela } \\
\text { Université de Montpelier } 1 \\
\text { BOLSista da CAPES }
\end{array}
$$

Membro da Equipe de Recherche sur L'IDENTITÉ ET LA Citoyenneté - ERIC, vinculada À École Doctorale DA FACULTÉ DE DROIT ADVOGADO 